\title{
Effect of Life Expectancy on Technological Development
}

\author{
Amandeep Singh, ${ }^{\text {a }}$ Kuldeep Kumar, ${ }^{\text {b Jasneet Kaur Wadhwa }}{ }^{c}$ and P. Arund \\ ${ }^{a}$ Department of Commerce, S.G.T.B. Khalsa College, University of Delhi, Delhi \\ 110007, INDIA \\ ${ }^{b}$ Department of Physics, S.G.T.B. Khalsa College, University of Delhi, Delhi 110007, \\ INDIA \\ 'Department of Economics, S.G.T.B. Khalsa College, University of Delhi, Delhi \\ 110007, INDIA \\ ${ }^{\mathrm{d}}$ Department of Electronics, S.G.T.B. Khalsa College, University of Delhi, Delhi \\ 110007 , INDIA \\ jasneetkw@sgtbkhalsa.du.ac.in
}

\begin{abstract}
The manuscript looks into the improvement of Life Expectancy and the number of invention patents filed in USA over the last two centuries. The direct proportionality between Technological advancement and Life Expectancy proves that the two indices are co-related. However, the co-relation when viewed with the lag present between Life Expectancy and Technological advancement indicates that the Technological advancement depends on the Life Expectancy and not visa versa. This notionally proves increased Life expectancy as the cause to Technological developments being made in USA.
\end{abstract}

Keywords. Life Expectancy, Technological Development, Cause and Effect

\section{Introduction}

In recent years there has been some work that suggests technology has helped in increasing the life expectancy of a country. This coincides with the popular notion that new medicines and advances in medicine if available to the population, helps in increasing life expectancy. In fact, Miah and Omar (2012) have shown that countries where technology usage is low, the life expectancy there is approximately half that of the developed nations. Similarly, Banerjee et al (2014) have shown that the recent economic growth of India has been driven by technological progress. While there is no doubt that technological advancements have improved our quality of life, the references mentioned clearly make the premise that technological advancements enhances the average life expectancy. This inference though seems trivial, however, is not unchallenged. 


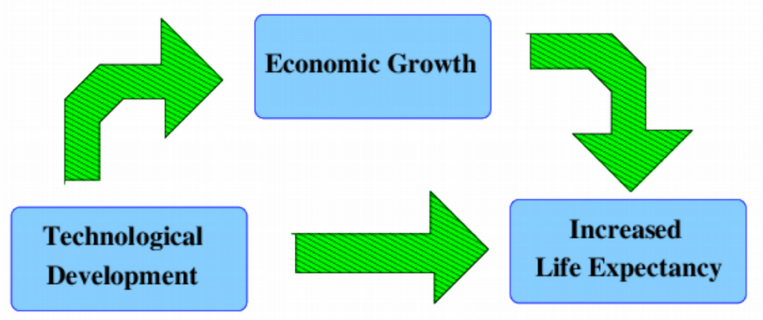

Alternative Model

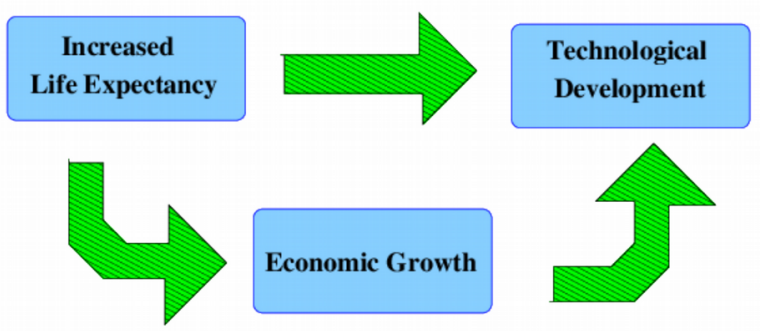

Figure 1: Pictorial representation of discussions in literature on whether (a) Technological development pushes life expectancy up or (b) Increased life expectancy results in Technological development.

To start with, in 1992 Galor and Stark (1992) emphasized that increasing life expectancy led to economic growth. Similar conclusion was arrived at by Cervellati and Sunde (2005), Acemoglu and Johnson (2007) using different models. In 2009, Belgi Turan in her work (2009) showed that even in under-developed countries, an increase in life expectancy shows a positive effect on growth. Growth in turn creates conditions conducive for technological development such as urbanization, employment avenues and investment availability for research. It is hence not a surprise that economically developed countries of the world like USA, Germany and other European countries, Japan and more recently China has been contributing to world technology. All in all, an alternative narrative arises that a prerequisite for technological development in a society is an enhancement in life expectancy. It is not as if this has not been suggested before. If Leonardo Di Vinci never died, lived in prime health and continued to acquire knowledge, won't his cumulative knowledge with ability to put it in practical use be more than all mortal mankind put together? It was in this context that the plot of one of the episodes (Star Trek Television episode, 1969) of the science fiction television series, Star Trek developed.

Summarizing the above two paragraphs, it is clear that the verdict is still not out. Figure 1 gives a schematic representation of the issues discussed above. As stated, the common notion is that technological developments enhances life expectancy (see figure 1a). Life expectancy may be a direct result of technological development or tangibly related by delivering economic growth whose fruits are increased life expectancy. The alternative model being discussed since 1992 and the subject of the present manuscript is shown in figure 1(b), where increased life expectancy leads to technological advancement. Again this maybe a direct consequence or via intermediate step of economic growth. 
Rephrasing what Galor and Stark (1992) had stated, the relation between Life expectancy and Technological development is transparent but which of this is the causality is not very clear. In this work, we investigate if enhanced life expectancy could be a cause or a driving force in technological development of a society. This question becomes important since economist and indeed policy makers would need to understand the mechanism of how their policies and plans would affect future generation and if it would pay dividends. Considering, especially in developing countries, where resources are merge to start with, it becomes imperative that policy makers decide whether to invest in health care and education which would automatically lead to growth and technological innovation or to import and buy technological innovations to promote economic growth and better health for the general population.

Table 1. List of major inventors and their age at which they made their contribution. List also gives the year of contribution to give an idea of any variation in average age at which contribution was made with year.

\begin{tabular}{|c|c|c|c|c|}
\hline S.No. & Name of Inventor & Contribution & $\begin{array}{c}\text { Year of } \\
\text { Invention }\end{array}$ & $\begin{array}{c}\text { Age at time } \\
\text { of Cont. }\end{array}$ \\
\hline 1. & Tim Bemers Lee & $\begin{array}{c}\text { WWW } \\
\text { (world wide web) }\end{array}$ & 1990 & 35 \\
\hline 2. & James Dyson & Bagless Vacuum Cleaner & 1983 & 36 \\
\hline 3. & Martin Cooper & Mobile Phone & 1973 & 45 \\
\hline 4. & Federico Faggin & Microprocessor (4004) & 1971 & 30 \\
\hline 5. & Gary Starkweather & Laser Printer & 1969 & 31 \\
\hline 6. & Robert Noyce & IC Fabrication & 1959 & 32 \\
\hline 7. & Jack Kilby & IC Fabrication & 1959 & 36 \\
\hline 8. & John Bardeen & Transistor (BJT) & 1947 & 39 \\
\hline 9. & Percy Spencer & Microwave Oven & 1945 & 51 \\
\hline 10. & William R Hewlett & Audio Oscillator & 1939 & 26 \\
\hline 11. & David Packard & Audio Oscillator & 1939 & 27 \\
\hline 12. & Ernst Ruska & Electron Microscope & 1933 & 27 \\
\hline 13. & Max Knoll & Electron Microscope & 1933 & 36 \\
\hline 14. & Alexander Fleming & Penicillin & 1928 & 48 \\
\hline
\end{tabular}




\begin{tabular}{|c|c|c|c|c|}
\hline 15. & Oleg Losev & Light Emitting Diode & 1927 & 24 \\
\hline 16. & Fritz Pfluemer & Magnetic Tape & 1927 & 46 \\
\hline 17. & John Logie Baird & Television & 1926 & 38 \\
\hline 18. & Frederick Banting & Insulin & 1921 & 30 \\
\hline 19. & Orville Wright & Airplane & 1903 & 32 \\
\hline 20. & Wilbur Wright & Airplane & 1903 & 36 \\
\hline 21. & Willis Carrier & Air-conditioner & 1902 & 26 \\
\hline 22. & Rudolf Diesel & Diesel Engine & 1897 & 39 \\
\hline 23. & Wilhelm C Rontgen & X-Ray & 1895 & 50 \\
\hline 24. & Marconi & Radio & 1894 & 20 \\
\hline 25. & Nicolus Tesla & A.C. Transmission & 1888 & 32 \\
\hline 26. & Otto Blathy & Transformer & 1885 & 25 \\
\hline 27. & Karl Benz & Petrol Car & 1885 & 41 \\
\hline 28. & Thomas Edison & $\begin{array}{c}\text { Electricity Distribution } \\
\text { (Gas Based) }\end{array}$ & 1882 & 35 \\
\hline 29. & Thomas Edison & Blub & 1879 & 32 \\
\hline 30. & Thomas Edison & Phonograph & 1877 & 30 \\
\hline 31. & Thomas Edison & Carbon Microphone & 1877 & 30 \\
\hline 32. & Alexander G. Bell & Telephone & 1876 & 29 \\
\hline 33. & Alfred Nobel & Dynamite & 1867 & 34 \\
\hline 34. & $\begin{array}{l}\text { William Robert } \\
\text { Glove }\end{array}$ & Fuel Cell & 1839 & 28 \\
\hline 35. & K. Macmillan & Pedal Bicycle & 1839 & 27 \\
\hline 36. & W.H.F. Talbot & Film Negative & 1835 & 35 \\
\hline 37. & Sadi Carnot & Steam Engine & 1824 & 28 \\
\hline
\end{tabular}


38.

Rane Laennec

Stethoscope

1816

35

In an initial attempt to test our hypothesis, we have collected data of major contributions made in invention/technology and pure science in the last two hundred years. Usual studies normally take science and technology together. However, it has been seen that development in pure science necessarily does not match development in technology or visa versa, hence collective rendering may result in some loss of information. Also, our selection of the reference time frame is based on the authentic documentation available as to the date of birth of the scientist/ inventor and his/her age at the time of the discovery/invention. Though important contributions were made to modern science since the $16^{\mathrm{h}}$ century, modern scientific and technological revolution was ushered in around the $19^{\text {th }}$ century, thus guiding us in selecting the period of 1800-2000 for the present study. Table 1 list the names of important inventions and their inventors between the period 1800-2000. The names were selected on the basis of the contribution made and the influence the invention has made on the society at large. Various polls have been made in recent years making inquiry as to the most important invention in the last century and so on. Of course the outcome of these poll depend on the target audience, their age etc. For example in a poll conducted by Roper Organization (1981) in 1981 among a very small target audience using Internet, the outcome was that the computer was considered the most important invention followed very closely by the air conditioner. Similarly, in a survey conducted by a website (https://m.ranker.com/list/most-importanthistorical-events-of-the-20th-century) the invention of the Internet polled the maximum votes as the most historical event of $20^{\text {th }}$ century. The Gallup/CNN/USA Today poll (http://www.pollingreport.com/20th.htm) conducted in December 1999, stated that the American audience considered the computer as the biggest invention followed by automobiles and electricity.

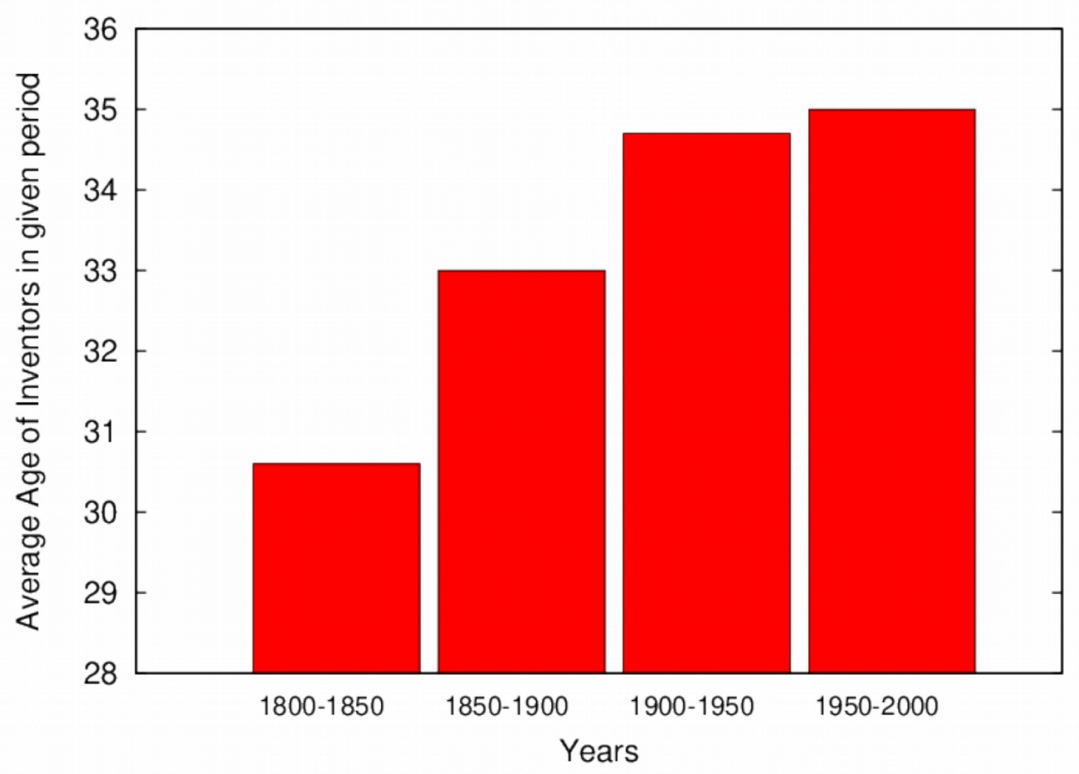

Figure 2: Histogram shows the increase in average age of inventors in the last two centuries divided into four periods of five decades each. 
Table 1 also lists the year that the invention was made and the age of the inventor at the time of invention. A cursory review of the list arranged in order of year of invention will show the age of the inventor has increased over the years. The data listed in Table 1 has been given in form of a graph (fig 2) to grasp its significance. The period between the years 1800 and 2000 has been divided into four periods of five decades each and the average age of the inventors of the period was determined. As can be seen from fig 2, the average age of the inventor has increased from 30 years in the period 1800-1850 to 35 years in the period 19502000. That is, over the last two centuries, the average age of the inventors has increased by 5 years. This in itself suggests that in future (assuming trend continues, in year 2200), inventions would be contributed by people whose average age would be near 40 . This result for any student of science and technology would not come as a surprise considering that for contributing anything new, one would need to have a comprehensive understanding of the developments made in the past. Every new discovery or invention is but a step forward in the long journey covered. Considering that modern science is an accumulation of more than three hundred years of knowledge, the time required to assimilate and appreciate it and then make ones own contribution would be a labor of time. Every fifty year of human knowledge seeming implies (on an average) an increase in age by additional year of the scientist/ inventors at which he/she would make a contribution. Clearly, this would imply that in increased life expectancy would be required for the scientist/ inventor to live to the age he or she would be in a position to contribute to technological advancement.

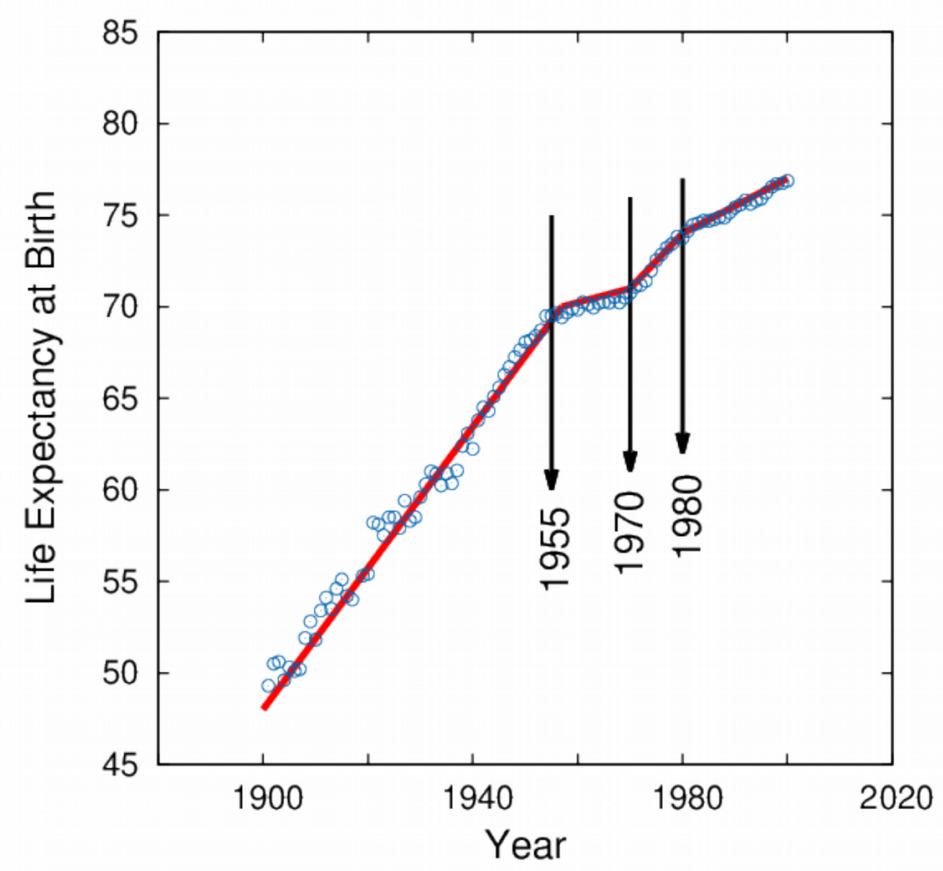

Figure 3: The variation of Life Expectancy at birth in USA between the year 1900 and 2000. Four distinct regions are visible, based on the rate of change. The steepest change lasts till 1955, with Region II and III ending at 1970 and 1980, respectively.

While this does forward our argument that increased life expectancy would lead to technological advancement, we need to remove any possibility of biasness in selection of inventor/ invention made in Table 1 and also do include the huge number of scientific and 
technological contributions made that may or may not have become a part of popular imagination. For this, we would require an indice for quantifying the scientific and technological advancements being made in a society. Various indices have been used over the years, such as counting the scientific papers published in peer reviewed journals per year to the number of patents filed in a year. While technology is driven by science and hence there would a correlation between pure science research paper output and technological development, however, publishing is essentially an academic exercise. In the present study we are going to quantify the technological development of a society and hence we select the number of patents being filed in every year as the relevant indice. A problem however, with quantifying a society's contribution to technology in terms of the number of patents filed in this study is that applications and in turn databases never record the age of the applicant.

The Life expectancy at birth is the statistical average time an person is expected to live. Average is never a good indicator, considering in a country, the life expectancy in urban and rural area might have a very large variation, hence an average might be very deceptive in such a case. Some argue that Life expectancy as an indicator fails to comment on the quality of life. However, life expectancy increases with drop in infant mortality. Falling infant mortality is a comment on the quality of health care given to the females and newly born in society, which in turn comments on the quality of the society. Hence, to the limited extent of this study which is testing a hypothesis using data of the USA, life expectancy maybe considered a useful indice/ indicator. The life expectancy at the time of birth for USA between 1900-2000 (Aries, 2010) is shown in fig 3. The graph shows an increase in life expectancy with the years, however the variation is not uniform. Based on the trend of the curve and rate of variation, the graph can be segregated into four distinct regions,

- Region I (till 1955),

- Region II (1955-1970),

- Region III (1970-1980), and

- Region IV (post 1980).

Compared to the steep variation seen in Region I, Region II shows a slowing down in increase of Life Expectancy. This might be due to the aftermath of WWII and the Korean war that started in 1950. The shallow variation of Region II is followed by a near steep growth in Life Expectancy during 1970-1980 period. This can be expected considering that the starting of this region marked the end of Vietnam war, the end of recession caused by government trying to cut down on budget deficit. The year 1970 also saw the US government passing the Occupational Safety and Health Act to ensure workers safety in work environment. The government's concern for public health was also reflected by banning radio and television advertisements of cigarettes in 1971. The Social Security Act of 1965-66 introducing Medicaid and Medicare for aged people ensured medical health care, pushing their life span. These and other such steps must have ensured the increase in life expectancy during the 19701980 period. The Higher Education Act of 1965, investing money in higher education and giving financial aid to students would have encouraged people with increased life expectancy to invest in higher eduction of their children, as modeled by Galor et al (2000) and Galor et al (2004).

The growth post 1980 (Region IV) is persistent however at a rate substantially and perceivably reduced rate. This may also be an indication of a saturation effect coming into play, i.e. USA might nearly be attaining the maximum life expectancy genetically possible for 
the human species. The red line in the figure shows best fits to the data of the four marked regions. Figure 4 shows the number of invention patents filed in United States of America (http://www.uspto.gov/web/offices/ac/ido/oeip/taf/h_counts.htm) between 1900-2000. The curve trend is very similar to that of USA's Life expectancy (fig 3), divisible into four regions.

- Region I (till 1970),

- Region II (1970-1985),

- Region III (1985-1995), and

- Region IV (post 1995).

All the regions are linear, and similar to the life expectancy with time trend the second region shows stagnation or slow growth (but still linear, between 1970 to 1985). As stated the curve is similar to the Life expectancy curve except that it chases it or lags by 15 years with in and around 2 years error. The fact that the trend in number of patents filed follows Life expectancy is clearly indicative that Technological innovations are an effect of the increased life expectancy. A direct proportionality without time lag would have indicated a co-relation between the two, however the time-lag shows a cause and effect relation between the two rather then mere co-relation. In the following section, we shall model and discuss the variation of patents filed as a function of life expectancy.

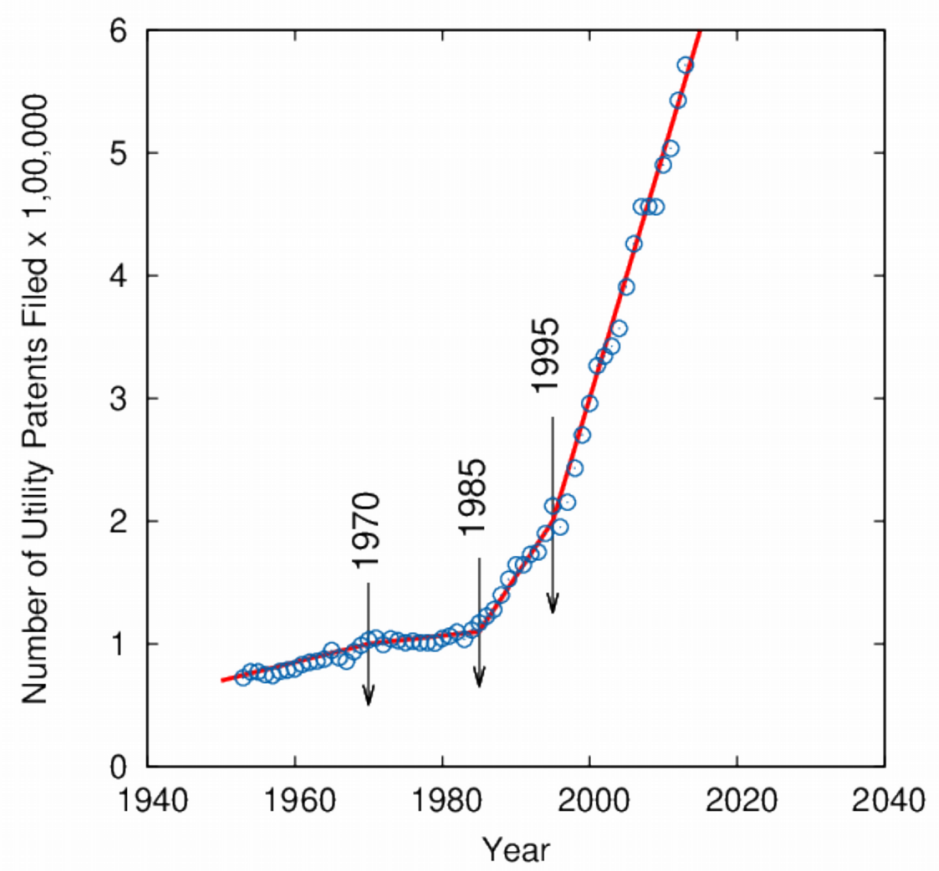

Figure 4: The number of utility patents filed in USA between the year 1940 and 2020. This curve also shows four distinct regions with Region's marked by arrows.

\section{A Simple Model}

To investigate on our hypothesis that an increasing life expectancy is a prerequisite for driving technological growth in a society, we subject the above to simple reductionist modeling. As explained above, rather then considering the century worth of data as a whole, we have divide 
the era in various periods or Regions. This division has been done based on visual examination where there is a distinct variation in the slope of the curves. The years marking the boundary of change was fine tuned by curve fitting the best line on the data and narrowing down the to an error of in and around 2 years on the boundary. As stated, the life expectancy (L.E.) during the four periods, are found to vary linearly with time and hence can be mathematically expressed as

$$
\text { L.E. }=m_{L . E .} \text { Years }+c_{L . E} \text {. }
$$

where $m_{\text {L.E. }}$ and $c_{\text {L.E. }}$ are the slope and intercept respectively. Similarly, the number of patents filed was also found to vary linearly with time and mathematically written as

$$
\text { Patents }=m_{\text {patents }} \text { Years }+c_{\text {patents }}^{\prime}
$$

where $\mathrm{c}_{\text {patents }}^{\prime}$ is written as

$$
c_{\text {patents }}^{\prime}=c_{\text {patents }}-m_{\text {patents }} \text { Lag }
$$

to accommodate the lag seen in number of patents filed when compared to the trend seen in the life expectancy. In other words, we are correcting the time scale (X-axis) of number of utility patents filed to match that of the life expectancy, giving the best fit line's equation as

$$
\text { Patents }=m_{\text {patents }}(\text { Years }- \text { Lag })+c_{\text {patents }}
$$

Table 2. Coefficients obtained by Curve fitting data of Life expectancy (fig 3) and number of utility patents filed (fig 4) with time in the four distinct regions marked by the arrows. Intercept in sixth column is reported for 15 year lag discussed in text.

\begin{tabular}{ccccccc}
\hline \multirow{2}{*}{ Sample } & \multicolumn{2}{c}{ Life Expectancy } & \multicolumn{2}{c}{ No. of Patents Filed } & \multicolumn{2}{c}{ From Eqn (7) } \\
\cline { 2 - 7 } & $\mathbf{m}_{\text {L.E. }}$ & $\mathbf{c}_{\text {L.E. }}$ & $\mathbf{m}_{\text {patents }}$ & $\begin{array}{c}\mathbf{c}_{\text {patents }} \\
\left(\mathrm{x} 10^{6}\right)\end{array}$ & $\mathbf{m}$ (fig 5) & $\mathbf{c}$ (fig 5) \\
\hline $\begin{array}{c}\text { Region } \\
\text { I }\end{array}$ & 0.42 & -750.42 & 1699.36 & -3.25 & 4046.1 & -239219.6 \\
\hline $\begin{array}{c}\text { Region } \\
\text { II }\end{array}$ & 0.07 & -74.39 & 631.10 & -1.14 & 9015.7 & -478787.5 \\
\hline $\begin{array}{c}\text { Region } \\
\text { III }\end{array}$ & 0.34 & -595.54 & 8773.50 & -17.30 & 25804.4 & -2064043.1 \\
\hline $\begin{array}{c}\text { Region } \\
\text { IV }\end{array}$ & 0.14 & -203.64 & 20792.85 & -40.98 & 148520.3 & -11047207.2 \\
\hline
\end{tabular}

Table 2 tabulates the constants obtained on least curve fitting data of the four regions (life expectancy w.r.t time, figure 3 and number of patents filed w.r.t. time, figure 4 . The corelation factor for all (eight) fits were found to be good (better than 0.98). As per the hypothesis of this work, i.e. increase in life-expectancy causes an accelerated technological development of the society, we would like to express eqn (4) as a function of L.E and not in terms of Years. For this, the independent variable of eqn (1) is written as 


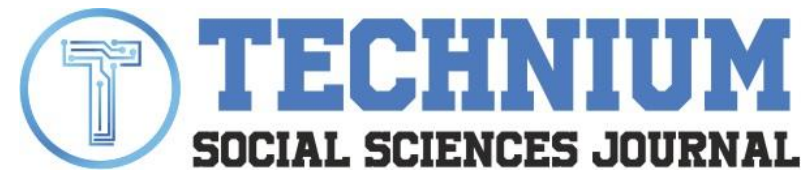

$$
\text { Years }=\left(\frac{L . E .-c_{L . E .}}{m_{L . E .}}\right)
$$

and substituted in eqn (4), to obtain

$$
\text { Patents }=m_{\text {patents }}\left[\left(\frac{L . E .-c_{\text {L.E. }}}{m_{\text {L.E. }}}\right)-L a g\right]+c_{\text {patents }}
$$

or

$$
\text { Patents }=\left(\frac{m_{\text {patents }}}{m_{\text {L.E. }}}\right) L . E .+\left[c_{\text {patents }}-\left(\frac{m_{\text {patents }}}{m_{\text {L.E. }}}\right) C_{L . E .}-m_{\text {patents }} L a g\right]
$$

Eqn (7) is, as expected, an equation of a line, suggesting a linear dependency of the number of utility patents filed with life expectancy. Again it has to be emphasized here that eqn (7) being an equation of a line only shows a co-relation between Life expectancy and number of utility patents filed. It is the proportionality with a constant lag between the two that established a cause and effect relation between life expectancy and technological innovations made in USA during the period of 1940-1995. Fig 5 plots the number of utility patents filed in USA as a function of Life expectancy after correction for the phase lag discussed above (using eqn 4). The four distinct regions are visible and the linearity (as given by eqn 7 ) is also evident. The lines in figure 5 are best fit lines to the data of the four regions. The co-relation factor of the linear best fit done to the data for Region III and IV were found to be around 0.97, giving good confidence on the interdependency of life expectancy and technological development. However, the co-relation between the best fit lines and data points of Region I and Region II were rather poor with $\mathrm{r}=0.43$ and 0.34 , respectively. To analyses the results further, we calculated the error contribution from the slope and the intercept separately (Barford, 1985) for Region I and Region II. While the relative slope errors were very low (less than $0.001 \%$ ), the relative intercept error for Region I and Region II were found to be 13.3 and $7.9 \%$, respectively (for Region III and Region IV the relative intercept error were less than $0.6 \%$ ). Thus, clearly the low co-relation between linear curved fitted and data points of Region I and Region II were due to error transmitted in evaluating the intercept. As far as the hypothesis that there is a co-relation between life expectancy and technological development is evident from the low relative slope error for all the four regions. Also, considering that this was established from the data corrected for the lag exhibited by the numbers indicating the technological development, the cause and effect relation between life expectancy and technological development is also substantiated. Interestingly the time lag of 15 years (with an error of in and around 2 years) between life expectancy and technological development matches the average years taken to finish schooling. A healthier population represented by increased life expectancy will invest more in their skills in order to earn higher wages and also invest in their children education. A healthy child will be able to attend the school and college and have higher cognition (Sachs, Malaney, 2002) and can contribute more towards development of innovative technology. Roselind et al (2016) have also shown a possible relation between intelligence and increased life expectancy. Returns from education are not instantaneous as accumulation of knowledge is a time consuming process and continuous in nature and returns are visible after a period of time. 


\section{(10) TECHNIUM}

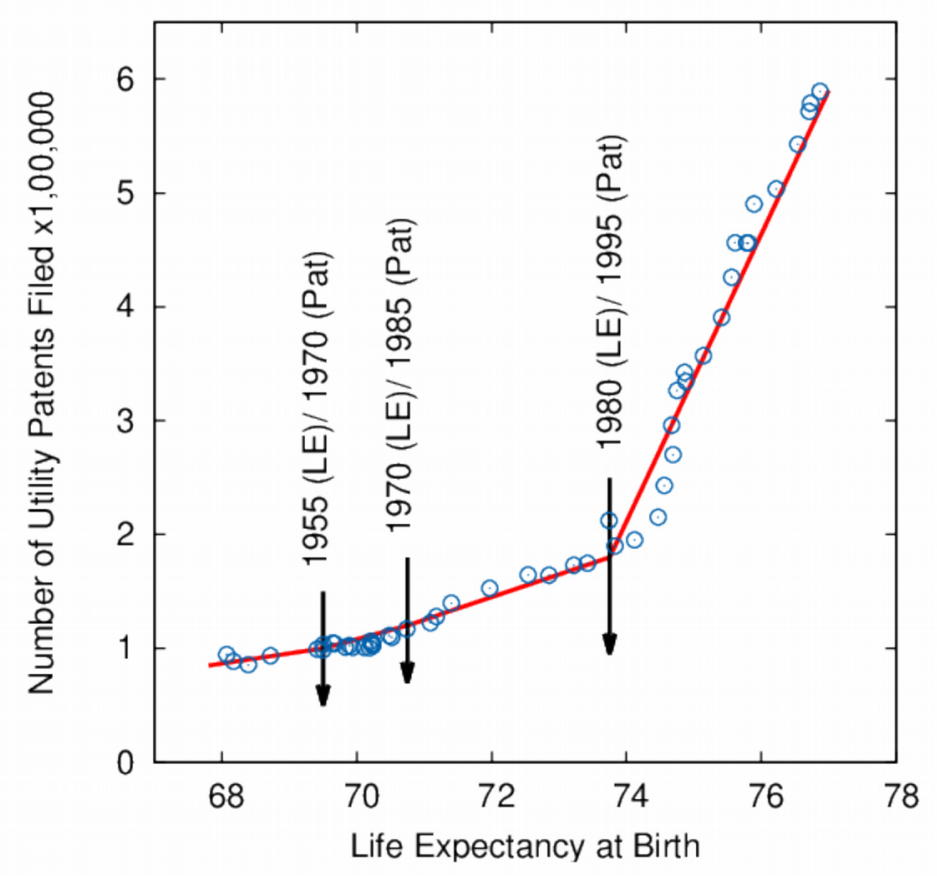

Figure 5: The number of utility patents filed in USA is shown as a function of Life expectancy.

Technological innovations are bought about by individuals with sharp intellects and a zeal to unrevealing the truth of nature and tame it for the use of humans. They are either motivated by personal experience (as in the case of Alexander Graham Bell who tried to invent a hearing aid for his deaf wife) or by an overwhelming drive to show (off) their ability to do what others cannot. However, such brilliance cannot occur in void and needs support from respective governments and society at large. Formal education and training though not a prerequisite, helps in nourishing talent (Edison was not educated in the sense he never finished schooling). However, learning from easily accessible information is a must and can be understood by the fact that most of the inventions (if not all) have been made in urban centers. Urban centers also ensure easy availability of material/ resources or components required for research and development. Considering setting up a research lab or center can be a costly affair, job guarantee and funding environment either by government or private companies becomes imperative for sustaining technological innovations. In recent years, the accumulation of personal wealth gained from technological innovations has become a driving force. In fact it is only after the enforcement of international patent laws or more specifically the Agreement on Trade-Related Aspects of Intellectual Property Rights (TRIPS) (1994) that the notion of creating wealth from knowledge became popular resulting in the forth region (post 1995 in figure 5), take-off in the number of patent applications filed. This along with the advent of Internet (www in the early 1990) giving rise to easy information and exchange of ideas, might be the compelling reason for steep increase in technological innovations made and increase in number of patents filed.

Hence, it is clear that there are numerous other factors over and above life expectancy that can effect the rate of technological innovations taking place in a society as manifested by the number of patents filed. However, whatever these numerated/ unenumerated factor are, they do not effect the linear relation between life expectancy and number of patents filed. 
They in fact only change the slope and intercept of linear fit, as was evident from figure 5. Eq (6) should hence be written as

$$
\text { Patents }=(m . L E+c) x f n\left(x_{1}, x_{2}, x_{3}, \ldots\right)
$$

where $f n\left(x_{1}, x_{2}, x_{3}, \ldots\right)$ represents the functional dependence of the various other factors, such as availability of funding, generation of wealth from invention etc, effecting the rate of technological development. We have further investigated our model in light of eqn (8). As claimed, we assume the function term to take a numerical value at each epoch year depending on the level of urbanization, government investment in research etc. Assuming that our analysis is with respect to Region I which ends in year 1955 and function term is normalized to unity, we can write eqn (8) is written as

$$
\text { Patents }=a\left(m_{\text {Region I. }} L E+c_{\text {Region I }}\right)
$$

where $a=1$. For minimum deviation for the values of slope and intercepts listed in Table 2, we find a for Region I, II and III as two (2), seven (7) and forty (40), respectively. The importance of this result is that it clearly establishes that variables such urbanization, government investments and funding etc can not be inserted as variables in a multiple linear regression model. The more complex nature of their contribution would need further investigation.

\section{Conclusion}

The paper challenges the conventional economic models that suggest technological advancement made in a society results in its economic growth which in turn leads to an increase in its population's life expectancy. An alternate model is suggested where it is argued that an improvement in life expectancy would lead to technological development. There has been such suggestions and studies in the past too, where a correlation between life expectancy and technological development was established. However, these studies failed to establish the cause and effect relationship between life expectancy and technological development, respectively. This paper concludes on the basis of modeling on data of USA over the last 150200 years, that the life expectancy is the cause and technological development is the effect. The technological development is quantified on the basis of number of utility Patents filed in a year. There is a fifteen year phase lag between life expectancy and technological advancement, with technological development lagging life expectancy. This clearly reflects that life expectancy leads to technological development. As explained in previous studies, the increased life expectancy leads to investment in education at individual and government level, which leads to development of human capital. However, the returns from human capital are visible only after sometime i.e. there is a requirement of some minimum years of education to acquire intellectual skill that can contributed to technological development. This seems to be the main reason behind the phase lag. Further, in this study, the graph has been segregated in to four regions Region I (till 1954), Region II (1955-1970) and Region III (1971-1980) and Region IV (1981-2000) on the basis of curve trend and rate of variation. These regions suggest that there are certain other factors such as government expenditure on research and development comes into picture and effects technological development, however these variables do not manifest as new variables of a multiple linear regression model. 


\section{References}

[1] M. MIAH, A. OMAR: Technology Advancement in Developing Countries in Digital Age. International Journal of Science and Applied Information Technology, ISSN 2278 - 3083, 1, 30 (2012).

[2] R. BANERJEE, S. S. ROY: Human capital, technological progress and trade: What explains India's long run growth?. Journal of Asian Economics, ISSN 1049-0078, 30, 15 (2014).

[3] ODED GALOR, ODED STARK: Life Expectancy, Human Capital Formation and PerCapital Income. Working Paper-Brown University (1992).

[4] MATTEO CERVELLATI, UWE SUNDE: Human Capital Formation, Life Expectancy and the Process of Development. The American Economic Review ISSN 0002-8282, 95, 1653 (2005).

[5] DARON ACEMOGLU, SIMON JOHNSON: Disease and Development: The Effect of Life Expectancy on Economic Growth. Journal of Political Economy ISSN 00223808, 115, 925 (2007) .

[6] BELGI TURAN: Life Expenctancy and Economic Development: Evidence from Microdata. Working paper (2009).

[7] Star Trek Television episode, "Requiem for Methuselah" (1969).

[8] BRUCE A. SHUMAN: Issues for Libraries and Information Science in the Internet Age. Libraries Unlimited ISBN-10: 1563088053

[9] https://m.ranker.com/list/most-important-historical-events-of-the-20th-century

[10] http://www.pollingreport.com/20th.htm

[11] ARIES E: United States life tables, 2006. National Vital Statistics Reports ISSN 15518930, 58, 1 (2010).

[12] O. GALOR, D.N. WEIL: Population, technology, and growth: From Malthusian stagnation to the demographic transition and beyond. The American Economic Review ISSN 0002-8282, 90, 806 (2000).

[13] O. GALOR, O. MOAV: From physical to human capital accumulation: Inequality and the process of development. Review of Economic Studies ISSN 1467-937X, 71, 1001 (2004) .

[14] http://www.uspto.gov/web/offices/ac/ido/oeip/taf/h_counts.htm

[15] N.C. BARFORD: Experimental Measurements, Precision, Error and Truth. Wiley (1985) New York.

[16] JEFFREY SACHS, PIA MALANEY: The Economic and Social Burden of Malaria. Nature ISSN 0028-0836 , 415.6872, 680 (2002).

[17] ROSALIND ARDEN, MICHELLE LUCIANO, IN J DEARY, CHANDRA A REYNOLDS, NANCY L PEDERSEN, BRENDA L PLASSMAN, MATT McGUE, KAARE CHRISTENSEN, PETER M VISSCHER: The association between intelligence and lifespan is mostly genetic. International Journal of Epidemiology. ISSN 0300-5771 , 45, 178 (2016) . 